\title{
autêntica
}

\author{
ARTIGOS
}

\section{Formação docente para a educação infantil: uma leitura do curso de pedagogia pós diretrizes curriculares}

Leandra Fernandes do Nascimento Maria Marina Dias Cavalcante

\begin{abstract}
RESUMO:
O estudo representa um recorte de uma pesquisa mais ampla realizada no Ceará, tendo como objetivo geral - analisar a organização curricular dos cursos de licenciatura em Pedagogia, em sete (7) Cursos de Pedagogia presenciais e um (1) EaD de uma Instituição de Ensino Superior multi campi. Caracteriza-se por ser uma pesquisa de abordagem qualitativa, realizada a partir da pesquisa documental - a Lei de Diretrizes e Bases da Educação Nacional - LDBEN 9394/1996, as Diretrizes Curriculares Nacionais para os cursos de Pedagogia de 2006 e a Resolução CNE/CP 2/2015, e, as Matrizes Curriculares. Os dados foram analisados à luz dos conhecimentos teóricos relacionados à Formação Docente, Currículo, e Educação Infantil. Os resultados apontam que a formação docente inicial dessa instituição precisa ser repensada, considerando não somente as exigências legais, mas que reveja seus conceitos, inclusive como instituição que oferece cursos presenciais. Nesse campo há que se refletir criticamente sobre os elementos oferecidos durante a formação do futuro professor para a Educação Infantil da educação básica brasileira.
\end{abstract}

PALAVRAS-CHAVE:

Formação de Professores; Educação Infantil; Currículo.

\section{TEACHER'S TRAINING FOR CHILD EDUCATION: READING THE PEDAGOGY COURSE POST CURRICULUM GUIDELINES}

\begin{abstract}
:
This research presents a snip from a wider research. This work has as general goal - analysis the curricular organization of the degrees in Pedagogy, it's in seven (7) face-to-face Pedagogy courses and one (1) EaD from a multi campus institution of higher education, having as legal documents of analysis the Law of Guidelines and Bases from National Education - LDBEN n 9394/1996, the National Curricular Guidelines for the Pedagogy courses from 2006 and the Resolution CNE/CP n²/2015. Characterize for being a qualitative research, collecting data from the teaching projects of the pedagogy degree's courses of a public institution of higher education of Ceará. Setting itself in a documental research. And for the data analysis it was used the curriculum's matrices. The data was analyzed based on the knowledges related to the teacher training, curriculum, and child education. The results shows that the initial teacher's training of this institution needs to be rethought, considering not just the legal requirements, but revising its conceptions, including as institution that offers face-to-face courses. On this area there are some things to review critically about the offered elements during the training of a future teacher for the child education of the Brazilian basic Education.
\end{abstract}

\section{KEY-WORDS:}

Teacher's Training; Child Education; Curriculum. 


\section{autêntica}

\section{INTRODUÇÃO}

A escola cearense se encontra conforme afirma Nóvoa (2009) transbordada de obrigações, porém não podemos desfocar de seu papel social, que é promover o acesso ao conhecimento acumulado historicamente pelo Homem, passando assim de geração em geração (SAVIANI, 2000; LIBANEO, 2001, 2006).

E é diante dessa realidade muitas vezes conflituosa que o professor se encontra, sendo fundamental prepará-lo para a realidade concreta. Assim, a formação docente acaba sendo mola propulsora para resignificar o contexto de suas práticas pedagógicas.

Pensando nessa realidade, a presente pesquisa propõe se aproximar do cenário da Educação Infantil, que configura como espaço inicial dos dilemas do sistema educacional brasileiro.

Diante desse cenário surge a seguindo pergunta - qual o tratamento dado aos conhecimentos formativos voltados para atender o futuro professor da Educação Infantil? E foi pensando em respondê-la que buscou investigar uma instituição pública do Ceará, observando o curso de Pedagogia oferecido na modalidade presencial e EaD.

Em outras palavras pretendeu-se analisar a organização curricular dos cursos de licenciatura em Pedagogia, enfocando no tratamento dado aos conhecimentos formativos para atender o futuro professor da Educação Infantil.

Caracteriza-se como uma pesquisa qualitativa, embora se faça uso de dados quantitativos oriundos das matrizes curriculares dessa instituição, se configurando como pesquisa documental.

Pretende-se assim, contribuir com os campos epistemológico e político em torno da Formação Docente e da Educação Infantil, procurando estabelecer uma discussão que promova a interseção entre esses campos.

Para tanto o presente artigo se encontra organizado em quatro seções: na primeira intitulada Formação docente para a Educação Infantil: apontamento da legislação em vigor, apresentando uma discussão a partir dos documentos legais sobre a formação docente que estão em vigência; na seção seguinte tem-se Pedagogo: o profissional da Educação Infantil, aqui aponta ainda que introdutoriamente um debate conceitual acerca das principais categorias teóricas desse estudo.

Seguindo, tem-se o Caminho metodológico da pesquisa, registrando os procedimentos metodológicos aqui utilizados; e, na quarta seção denominada de a Formação docente inicial nos cursos de Pedagogia - presencial e EaD: dialogando com os dados, se apresenta os achados dessa pesquisa, que embora os cursos estejam na mesma instituição o debate em torno da Educação Infantil é particular em cada curso e em cada modalidade.

\section{FORMAÇÃO DOCENTE PARA A EDUCAÇÃO INFANTIL: APONTAMENTO DA LEGISLAÇÃO EM VIGOR}

A Lei de Diretrizes e Bases da Educação Nacional - LDBEN 9394/1996 é um documento de quase duas décadas, que vem ao longo desse período orientando a oferta da educação brasileira em todos os níveis, etapas e modalidades. Mas, nesse estudo procurou-se destacar a Educação Infantil, que de acordo com o artigo $29^{\circ}$ é caracterizada como a primeira etapa da educação básica, tendo como finalidade o desenvolvimento 


\section{DOCENTE}

\section{autêntica}

integral da criança de até 5 (cinco) anos, em seus aspectos físico, psicológico, intelectual e social, complementando a ação da família e da comunidade, atualização decorrente da lei 12.796/2013. Isso não é uma tarefa fácil, implicando uma escola que esteja atenta ao seu papel de promover uma educação infantil, se tornando efetivamente significativa.

Nesse contexto, a formação docente passa a representar o calcanhar de Aquiles nessa discussão, tendo no currículo um aspecto político que merece ser considerado no interior desse debate, principalmente, por entender que sem ele não tem como avançá-la.

A LDBEN 9394/1996 aponta a necessidade da formação docente. Desse modo, no artigo $62^{\circ}$ afirma que a formação de docentes para atuar na educação básica far-se-á em nível superior, em curso de licenciatura, de graduação plena, em universidades e institutos superiores de educação, admitida, como formação mínima para o exercício do magistério na educação infantil e nos 5 (cinco) primeiros anos do ensino fundamental, a oferecida em nível médio na modalidade normal. Vale destacar que o presente estudo se centrará no curso de licenciatura de nível superior.

No mesmo artigo, terceiro parágrafo, o documento em questão destaca que a formação inicial de profissionais de magistério dará preferência ao ensino presencial, sendo subsidiado pelo uso de recursos e tecnologias de educação a distância - EaD. Embora a ênfase dada a formação inicial presencial considerou-se também o ensino a distância nessa pesquisa.

Por fim, no artigo $65^{\circ}$ a formação docente, exceto para a educação superior, incluirá prática de ensino de, no mínimo, 300 horas. Isso significa que os cursos promotores de formação inicial presencial ou EaD deverão ter em seu currículo a preocupação de ter componentes curriculares que tenham essa natureza.

Outro documento que merece igual importância é a Resolução CNE/CP 1/2006 que traz o artigo $3^{\circ}$ destacando as competências do curso de Pedagogia, onde,

o estudante de Pedagogia trabalhará com um repertório de informações e habilidades composto por pluralidade de conhecimentos teóricos e práticos, cuja consolidação será proporcionada no exercício da profissão, fundamentando-se em princípios de interdisciplinaridade, contextualização, democratização, pertinência e relevância social, ética e sensibilidade afetiva e estética.

$\mathrm{O}$ artigo $4^{\circ}$ afirma que o curso de Pedagogia destina-se à formação de professores para exercer funções de magistério na Educação Infantil e nos anos iniciais do Ensino Fundamental, nos cursos de Ensino Médio, na modalidade Normal, de Educação Profissional na área de serviços e apoio escolar e em outras áreas nas quais sejam previstos conhecimentos pedagógicos. O documento segue destacando outras atribuições do pedagogo e estabelece ainda que as atividades docentes compreendem a participação na organização e gestão de sistemas e instituições de ensino, englobando nesse mesmo artigo:

I - planejamento, execução, coordenação, acompanhamento e avaliação de tarefas próprias do setor da Educação; II - planejamento, execução, coordenação, acompanhamento e avaliação de projetos e experiências educativas não-escolares; III - produção e difusão do conhecimento científico-tecnológico do campo educacional, em contextos escolares e não-escolares. 


\section{autêntica}

E centrando-se na temática destaca o artigo $5^{\circ}$, o qual aponta que o egresso do curso de Pedagogia deverá estar apto segundo o inciso II para compreender, cuidar e educar de crianças de zero a cinco anos, de forma a contribuir, para o seu desenvolvimento nas dimensões, entre outras, física, psicológica, intelectual, social.

Os trechos destacados evidenciam o amplo campo de atuação profissional que hoje se coloca ao egresso dos atuais cursos de Pedagogia, o qual supera, e muito, o universo escolar e, ao mesmo tempo, explicita o complexo e ambíguo perfil profissional do Pedagogo.

O artigo $7^{\circ}$ aponta que o curso de Pedagogia terá a carga horária mínima de 3.200 horas de efetivo trabalho acadêmico, sendo reservado, de acordo com o inciso II, 300 horas dedicadas ao Estágio Supervisionado prioritariamente em educação Infantil e nos anos iniciais do Ensino Fundamental, contemplando também outras áreas específicas, se for o caso, conforme o projeto pedagógico da instituição.

Sobre isso o artigo $8^{\circ}$, inciso IV, reafirma que o estágio curricular a ser realizado, ao longo do curso, deve assegurar aos graduandos experiência de exercício profissional, em ambientes escolares e não-escolares, ampliando e fortalecendo atitudes éticas, conhecimentos e competências, dando ênfase na Educação Infantil e nos anos iniciais do Ensino Fundamental, prioritariamente.

Recentemente ocorreram novas intervenções no currículo trazidas pela Resolução CNE/CP 2/2015 que define as Diretrizes Curriculares Nacionais para a formação em nível Superior (cursos de licenciatura, curso de formação pedagógica para graduados e cursos de segunda licenciatura) e para a formação continuada.

Parafraseando o artigo $9^{\circ}$ é importante perceber que os cursos de formação inicial para a educação básica, em nível superior, se realizam em três possibilidades: I - cursos de graduação de licenciatura; II - cursos de formação pedagógica para graduados não licenciados; e, III - cursos de segunda licenciatura. Tal discussão se centra na primeira possibilidade formativa.

E segue afirmando no mesmo artigo que:

$\S 1^{\circ} \mathrm{A}$ instituição formadora definirá no seu projeto institucional as formas de desenvolvimento da formação inicial dos profissionais do magistério da educação básica articuladas às políticas de valorização desses profissionais e à base comum nacional explicitada no capítulo II desta Resolução.

$\S 2^{\circ} \mathrm{A}$ formação inicial para o exercício da docência e da gestão na educação básica implica a formação em nível superior adequada à área de conhecimento e às etapas de atuação.

$\S 3^{\circ} \mathrm{A}$ formação inicial de profissionais do magistério será ofertada, preferencialmente, de forma presencial, com elevado padrão acadêmico, científico e tecnológico e cultural.

Conforme se evidencia nesta resolução o foco se mantém para a formação dos profissionais do magistério, agora justificando a importância da formação inicial e da formação continuada daqueles:

Artigo $3^{\circ}$ - A formação inicial e a formação continuada destinam-se, respectivamente, à preparação e ao desenvolvimento de profissionais para funções de magistério na educação básica em suas etapas - educação infantil, ensino fundamental, ensino médio - e modalidades - educação de jovens e adultos, educação especial, educação profissional e técnica de nível médio, educação escolar indígena, educação do campo, educação escolar quilombola e educação a distância - a partir de compreensão 
ampla e contextualizada de educação e educação escolar, visando assegurar a produção e difusão de conhecimentos de determinada área e a participação na elaboração e implementação do projeto político-pedagógico da instituição, na perspectiva de garantir, com qualidade, os direitos e objetivos de aprendizagem e o seu desenvolvimento, a gestão democrática e a avaliação institucional.

Nesse sentido, há a defesa de uma formação que compreenda ampla e contextualmente a educação. Complementando essa concepção segue o artigo $5^{\circ}$, o qual afirma que as diretrizes expressam opções para um currículo que favoreça a vivência da realidade social e cultural para o exercício da cidadania e qualificação para o trabalho.

Por sua vez, o artigo $8^{\circ}$, considera que o egresso desse curso deverá ter, inciso II, a concepção ampla e contextualizada de ensino e processos de aprendizagem e desenvolvimento destes, incluindo aqueles que não tiveram oportunidade de escolarização na idade própria. Vale destacar que esse artigo traz treze (13) incisos, que vão apresentando as atribuições que deveram está consolidada após a conclusão do seu curso de licenciatura.

Em relação à Educação Infantil, a Resolução CNE/CEB 5/2009 define no artigo $3^{\circ}$ o currículo como sendo,

... um conjunto de práticas que buscam articular as experiências e os saberes das crianças com os conhecimentos que fazem parte do patrimônio cultural, artístico, ambiental, científico e tecnológico, de modo a promover o desenvolvimento integral de crianças de 0 a 5 anos de idade.

Diante dos apontamentos legais apresentados, se observa que é exigido do futuro professor capacidades múltiplas para atuar na complexidade das escolas e dos sistemas de ensino, demandando, portanto, uma sólida formação.

\section{PEDAGOGO: O PROFISSIONAL DA EDUCAÇÃO INFANTIL}

A Educação Infantil é a primeira etapa da educação formal, tendo como finalidade o desenvolvimento integral da criança de até 5 (cinco) anos, em seus aspectos físico, psicológico, intelectual e social, complementando a ação da família e da comunidade, conforme o artigo $29^{\circ}$ da LDBEN 9394/1996).

Vale destacar que a LDBEN 9394/1996 no artigo $4^{\circ}$, inciso II, aponta que educação infantil gratuita às crianças de até 5 (cinco) anos de idade. E parafraseando o artigo $11^{\circ}$, a referida etapa é dever dos municípios, o qual reforçado pelo inciso $V$ é incumbido de oferecer a educação infantil em creches e pré-escolas.

Mais adiante no artigo $30^{\circ}$ destaca que a Educação Infantil deve ser oferecida em: I - creches, ou entidades equivalentes, para crianças de até três anos de idade; II - pré-escolas, para as crianças de 4 (quatro) a 5 (cinco) anos de idade.

Para atingir tal finalidade a escola conta com o professor licenciado em pedagogia - o pedagogo, que tem o propósito de oferecer elementos que estimule os aspectos objetivados na lei para a etapa em questão.

Nesse contexto é preciso um profissional que possua uma formação docente inicial que alicerce suas futuras práticas pedagógicas (VEIGA, 1994; CUNHA, 1989) e que durante o processo de formação, conforme apontado por Pimenta (2009), seja ressaltado a importância de estudos articulados sobre Educação e Pedagogia, 


\section{autêntica}

considerando-os fundamentais para investigar a prática e construir "saberes pedagógicos". O "saber pedagógico" não se fundamenta no "saber disciplinar" e é diferente do "conhecimento pedagógico". Portanto, o "conhecimento pedagógico" é aquele conhecimento elaborado por pesquisadores e teóricos da Educação, já o "saber pedagógico" é o "saber construído pelo professor no exercício da docência" (PIMENTA, 2009).

Tardif (2002) é outro autor que considera a formação docente um aspecto extremamente importante para o desenvolvimento do processo de ensino/aprendizagem, pois segundo o autor o professor se constitui por diversos saberes que vão se acumulando antes mesmo de iniciado seu processo formativo formal, o que chamou de saber investido.

Pimenta $(2011,2014)$ ensina que a formação não deve ser orientada por princípios dominantes e sem qualquer articulação com a realidade. Considera que o professor em formação e em exercício da prática prossegue adquirindo condições para contribuir para transformar o mundo social. Compreende que os professores devem vivenciar na formação experiências que os ajudem a compreender o contexto histórico/social/cultural/ institucional nos quais ocorre a sua atividade docente.

A autora citada contesta a concepção de professor como "técnico reprodutor de conhecimentos e/ou monitor de programas pré-elaborados" e ressalta a importância do papel que desempenham na constituição da cidadania dos educandos, considerando fundamental essa participação, que concorre para a superação das desigualdades escolares. Assim entende a educação como processo de humanização, uma prática social realizada por todas as instituições da sociedade; sendo a escola o espaço de desenvolver um trabalho coletivo e interdisciplinar com alunos e professores; com o conhecimento numa perspectiva de inserção crítica e transformadora (PIMENTA, 2009).

Para Libâneo $(2001,2006)$ o professor deve ter o domínio sólido e duradouro dos conteúdos. Essa ideia não se confunde com o professor conteudista, mas com o profissional que é autor da sua prática e possui sólida formação teórico-prática e autonomia para decidir e intervir no processo de ensino e aprendizagem (LIBÂNEO, 2011).

De acordo com Farias et al (2014) o "saber ensinar" requer o domínio não somente do campo disciplinar da formação - dos conteúdos - mas também "saber ensinar" supõe o "domínio do campo pedagógico".

Nesse sentido, o professor deixa de ser "mero instrutor" responsável pelo "repasse objetivo e normativo dos conhecimentos socialmente reconhecidos" e tem contribuição efetiva na formação de sujeitos que possam "descobrir os múltiplos saberes e significados" do mundo (FARIAS et al, 2014).

Desse modo, a preocupação com a formação de professores deve priorizar a promoção de uma educação pública de qualidade, como concebida por Davis e Grosbaum (2002). Sendo assim, a formação de professores em cursos superiores deve ser considerada o alicerce, a base de formação sobre a qual se edificará seu processo formativo e sua condição de exercício profissional.

Observa-se diante do que fora exposto que a formação docente inicial além de uma exigência burocrática configura como elemento essencial na vida do futuro professor. Nessa perspectiva, percebe-se como é fundamental uma formação de professores de qualidade, a qual os prepare para lidar e contribuir com as questões sociais. 


\section{autêntica}

A formação inicial do professor para o magisterio se apresenta como,

[...] a trajetória que ele percorre do momento em que inicia a escolaridade (na Educação Infantil) até sua conclusão, que pode ocorrer no Ensino Médio ou no Ensino Superior. Nesse processo espera-se que ele adquira qualificação mínima e certificação, habilitando-se legal e tecnicamente para o exercício profissional (FUSARI, 1997, p.157).

Nessa perspectiva compreende que mais do que obter uma certificação legal para o exercício da atividade docente, espera-se que a formação inicial proporcione, diante do foco dessa pesquisa, uma formação de professores para a educação Infantil, desenvolvendo nos futuros professores habilidades, atitudes, valores e conhecimentos que Ihes possibilitem construir permanentemente seus saberes, suas práticas e sua identidade.

Nesse sentido, a formação é entendida nesta investigação como parte integrante do desenvolvimento pessoal e profissional do professor. Tal processo segundo Zabalza (2004, p.145) "requer atualizações constantes que capacitem os indivíduos para dar uma resposta adequada ao instável mundo dos novos cenários de trabalho".

Esse autor considera também que a formação pedagógica visa contribuir para o aperfeiçoamento das práticas docentes, destacando que as novas modalidades de formação abrangem eixos básicos, tais como: a reflexão sobre a prática ou revisão sistemática do próprio exercício profissional; e a unidade entre teoria e prática profissional real, ou seja, a relação entre as instituições formativas e os cenários reais de trabalho - as escolas.

Na concepção de Moreira (2010) a Educação institucionalizada precisa atender a sociedade contemporânea como sendo multicultural e possuidora de diferenças relacionadas com a classe social, gênero, etnia, orientação sexual, cultura e religião, que se expressam nas distintas esferas sociais, aspectos que também não podem ser desconsiderados no discurso educacional. Nesse sentido, visualiza um currículo atento as necessidades da sociedade.

Assim, qualquer que seja a proposta curricular há intencionalidades em relação aos indivíduos, a cultura herdada, a sociedade, na qual estão inseridos. Em cada período o que se considera como conteúdo de ensino reflete uma visão, da cultura e do papel social da educação, fornecendo ferramentas para que os professores compreendam o papel que a escolaridade está a cumprir, assim "o que se ensina, se sugere ou se obriga a aprender expressa os valores e funções que a escola difunde num contexto social e histórico concreto" (SACRISTÁN, 2007, p. 150).

Pelo exposto é possível verificar que o curso de Pedagogia tem, na atualidade, um duplo e complexo desafio: atender, por um lado, ao perfil formativo determinado pela legislaçao educacional, e, por outro, as reais demandas da sociedade contemporânea.

Diante desses desafios, os currículos dos cursos de Pedagogia têm sido reorganizados, de maneira mais intensa a partir de 2006, visando atender às determinações das Diretrizes Curriculares Nacionais. Entretanto, é salutar considerar que o presente esforço não tem garantido a ampliação da qualidade da formação do professor no país; ao contrário, estudos atuais têm evidenciado que essa tem se apresenta muito comprometida (GATTI e BARRETO, 2009 e LIBÂNEO, 2010).

É importante que os direitos sejam estabelecidos e efetivados, não ficando apenas no discurso, logo é preciso cuidar da formação docente e das condições para a oferta da educação formal brasileira de qualidade (LIBÂNEO, 2010). 


\section{autêntica}

\section{CAMINHO METODOLÓGICO}

O presente estudo investigou uma (1) instituição de ensino superior do estado do Ceará, se centrando nos cursos de Pedagogia nas modalidades - presencial e EaD, tendo como perspectiva a formação do futuro professor que atuará na Educação Infantil. Desse modo, tratou-se de um estudo exploratório de abordagem Qualitativa realizado em sete (7) cursos de Pedagogia presenciais e de um (1) EaD, representando um recorte, de uma pesquisa mais ampla, de uma Instituição de Educação Superior (IES).

Nesse sentido, caracterizando-se por uma pesquisa de abordagem qualitativa (BOGDAN; BIKLEN, 1982), pois se preocupou em responder - qual o tratamento dado aos conhecimentos formativos voltados para atender o futuro professor da Educação Infantil? Primeira etapa da educação básica, no estado do Ceará, sendo os Projetos Pedagógicos dos Cursos - PPC de Pedagogia dessa instituição de ensino superior a base desse estudo. E embora faça uso do quantitativos de disciplinas e de suas respectivas cargas horárias a perspectiva de análise é qualitativa, destacando o fenômeno e procurando interpretá-lo como outrora destacou Minayo (2012).

Já Gil (2002) entende que esse tipo de pesquisa aprimora as ideias ou a descoberta de intuições, se apoiando inicialmente na pesquisa bibliográfica, a qual demanda um levantamento bibliográfico, que de acordo com Gondim (1999), tem por objetivo principal conhecer os trabalhos anteriores que tratam de objetos comparáveis, de modo a subsidiar a preparação da revisão teórica, isso significa, que é extremamente importante fazer um apanhado geral dos trabalhos realizados, com a finalidade de coletar um maior número de concepções sobre o assunto para melhor compreensão do estudo em andamento.

A pesquisa bibliográfica recorre a um discurso argumentativo, sendo assim, o pesquisador apresenta os principais conceitos, categorias e noções com as quais vai trabalhar, estabelecendo um diálogo com os autores sobre os quais fez a revisão da bibliográfica (MINAYO, 2012). Em outras palavras esse primeiro momento da pesquisa se caracteriza pela análise do arcabouço literário de uma determinada temática. De acordo com Gil (2002) é desenvolvida a partir de material já elaborado, constituído, principalmente de livros e artigos científicos.

Salienta que o presente estudo se ancorou principalmente na pesquisa documental constituindo-se em uma técnica importante na pesquisa qualitativa, seja complementando informações obtidas por outras técnicas, seja desvelando aspectos novos de um tema ou problema (LUDKE; ANDRÉ, 1986). Nesse sentido, a pesquisa promoveu uma análise dos projetos pedagógicos dos cursos de Pedagogia - presencial e em EaD de uma dada instituição de ensino superior.

Sendo assim, a análise documental favorece a observação do processo de maturação ou de evolução de indivíduos, grupos, conceitos, conhecimentos, comportamentos, mentalidades, práticas, entre outros a partir de fontes primarias ou secundarias (CELLARD, 2008).

Nesse caso, vale destacar que se fez uso de fontes secundárias. Diante desse tipo de fonte o investigador não intervém, visto que tudo está dado, sua principal preocupação é manter a imparcialidade diante dos documentos.

Para Phillips (1974), documentos são quaisquer materiais escritos que possam ser usados como fonte de informação sobre o comportamento humano. Entretanto, esses conceitos, vinculados à materialidade, se 


\section{autêntica}

apresentam ampliados na contemporaneidade, diante dos formatos tecnológicos, e desse modo, os documentos digitais também são validados. Desse modo, se justifica o uso de sites na internet para consolidação dos dados na presente pesquisa.

Após a coleta dos dados nos PPCs da instituição de ensino, guiada por um instrumento que centrou nas Matrizes Curriculares encontradas nos sites do E-MEC e da instituição pesquisada. Na sequência foram organizados no Sistema N* VIVO e analisados à luz das categorias: formação docente e currículo, gerando gráficos que serão apresentados e analisados a seguir.

\section{A FORMAÇÃO DOCENTE INICIAL NOS CURSOS DE PEDAGOGIA - PRESENCIAL E EAD: DIALOGANDO COM OS DADOS}

Nesta seção tem o propósito de realizar a apresentação e a análise dos dados coletados nas matrizes curriculares dos cursos de licenciatura em Pedagogia investigados em uma mesma instituição de natureza pública estadual, tendo como horizonte o objetivo deste trabalho.

Sendo assim, se concentrara nas seguintes categorias de análise: Conhecimentos relativos à Educação Infantil, Conhecimentos relacionados com a Educação Infantil, e, Estágio supervisionado na Educação Infantil.

Os dados obtidos são aqui apresentados por meio de quadros que revelam como se organizam os currículos desses cursos, identificando os espaços ali destinados à formação do professor para atuar na Educação Infantil.

Desse modo, segue a caracterização dos cursos foco dessa investigação: sete (7) oferecidos na modalidade presencial $(\mathrm{C} 1, \mathrm{C} 2, \mathrm{C} 3, \mathrm{C} 4, \mathrm{C} 5, \mathrm{C} 6, \mathrm{C} 7)$ e um (1) organizado à distância (C8).

QUADRO 1 - CARACTERIZAÇÃO DOS CURSOS DE PEDAGOGIA

\begin{tabular}{|c|c|c|c|c|c|}
\hline Curso & $\begin{array}{c}\text { Carga Horária } \\
\text { Total }\end{array}$ & $\begin{array}{c}\mathbf{N}^{\circ} \text { disciplinas } \\
\text { obrigatórias }\end{array}$ & Curso & $\begin{array}{c}\text { Carga Horária } \\
\text { Total }\end{array}$ & $\begin{array}{c}\mathbf{N}^{\circ} \text { disciplinas } \\
\text { obrigatórias }\end{array}$ \\
\hline C1 & 3.315 & 43 & C5 & 3.247 & 49 \\
\hline C2 & 3.247 & 49 & C6 & 3.230 & 37 \\
\hline C3 & 3.264 & 43 & C7 & 3.281 & 47 \\
\hline C4 & 3.213 & 39 & C8 & 3.230 & 42 \\
\hline
\end{tabular}

Fonte: Banco de dados do PERFORMA.

Diante do exposto no quadro, em relação à carga horária, todos os cursos sondados apresentam o mínimo exigido pela legislação educacional em vigor que é de $3.200 \mathrm{~h}$.

Com essa breve apresentação do perfil dos cursos investigados segue-se para os dados que competem especificamente às disciplinas obrigatórias que apresentam em seu programa objetivos direcionados à Educação Infantil. Nesse contexto, aponta-se a primeira categoria de análise.

\section{a) Conhecimentos Relativos à Educação Infantil}

As disciplinas que compõem essa categoria referem-se àquelas especificas ao ensino com crianças até 5 anos, voltadas portanto, para a formação do futuro professor da Educação Infantil. 


\section{autêntica}

QUADRO 2 - DISTRIBUIÇÃO DAS DISCIPLINAS DE EDUCAÇÃO INFANTIL NOS CURSOS INVESTIGADOS.

\begin{tabular}{|c|c|c|c|}
\hline Curso & Conhecimentos relativos à Educação Infantil & Otd & $\begin{array}{c}\text { Cargá } \\
\text { horária }\end{array}$ \\
\hline C1 & Fundamentos da Educação Infantil & 01 & $68 \mathrm{~h}$ \\
\hline C2 & Educação Infantil & 01 & $68 \mathrm{~h}$ \\
\hline C3 & Educação Infantil I; Educação Infantil II & 02 & $136 \mathrm{~h}$ \\
\hline C4 & Educação Infantil & 01 & $68 \mathrm{~h}$ \\
\hline C5 & $\begin{array}{c}\text { Fundamentos da Educação Infantil; Saberes e práticas na Educação } \\
\text { Infantil }\end{array}$ & 02 & $136 \mathrm{~h}$ \\
\hline C6 & - & 00 & 00 \\
\hline C7 & $\begin{array}{c}\text { Saberes e Práticas da Educação Infantil I: Lógica Matemática; } \\
\text { Saberes e Práticas da Educação Infantil II: Linguagens e códigos; } \\
\text { Saberes e Práticas da Educação Infantil III: Identidade Social } \\
\text { e Cultural; Saberes e Práticas da Educação Infantil IV: Vida e } \\
\text { Natureza; Psicologia do Desenvolvimento Infantil; Fundamentos da } \\
\text { Educação Infantil; Aquisição da linguagem }\end{array}$ & 07 & $68 \mathrm{~h}$ \\
\hline C8 & $\begin{array}{c}07 \\
476 h\end{array}$ & \\
\hline
\end{tabular}

Fonte: Banco de dados do PERFORMA.

Observando o presente quadro verifica-se o número reduzido de disciplinas ofertadas nos cursos presenciais que visam ao aperfeiçoamento dos conhecimentos e habilidades do professor para o ensino de crianças nessa primeira etapa da Educação Básica.

Apenas o curso com o ensino à distância C8 apresentou mais de duas disciplinas no currículo desse curso, que contempla uma sequência de conteúdo que proporcionam uma fundamentação teórico/prática capaz de garantir um futuro professor atento ao desenvolvimento das crianças em suas habilidades e dimensões sócio-culturais.

O curso C6, por sua vez ganha destaque nesse quadro por não apresentar índices quantitativos. No entanto, com as próximas observações é que poderemos apontar para uma desvalorização ou não do currículo desse curso para a educação infantil. Até o momento, pode-se dizer que não foram identificadas disciplinas que apresentaram em seu programa elementos destinados apenas à Educação Infantil.

\section{b) Conhecimentos Relacionados com a Educação Infantil}

Para a distribuição das disciplinas nesta categoria foram consideradas apenas aquelas que especificaram, no nome ou no programa da disciplina, alguma relação com a Educação Infantil. 


\section{autêntica}

QUADRO 3 - DISTRIBUIÇÃO DAS DISCIPLINAS RELACIONADAS À EDUCAÇÃO INFANTIL

\begin{tabular}{|c|c|c|c|}
\hline CURSO & Conhecimentos relacionados com a Educação Infantil & QTD & $\begin{array}{l}\text { CARGA } \\
\text { HORÁRIA }\end{array}$ \\
\hline C1 & $\begin{array}{l}\text { Fundamentos da leitura e da escrita; Língua Portuguesa I na } \\
\text { Educação Infantil e nos Anos iniciais do Ensino Fundamental; } \\
\text { Matemática I na Educação Infantil e nos Anos Iniciais do Ensino } \\
\text { Fundamental; Língua Portuguesa II na Educação Infantil e nos Anos } \\
\text { Iniciais do Ensino Fundamental; Matemática II na Educação Infantil } \\
\text { e nos Anos Iniciais do Ensino Fundamental; História e Geografia I } \\
\text { na Educação Infantil e nos Anos Iniciais do Ensino Fundamental; } \\
\text { Ciências Naturais I na Educação Infantil e nos Anos Iniciais do } \\
\text { Ensino Fundamental; Corporeidade e psicomotricidade na Educação; } \\
\text { Arte-Educação }\end{array}$ & 09 & $612 \mathrm{~h}$ \\
\hline $\mathrm{C} 2$ & $\begin{array}{c}\text { Arte-Educação; Alfabetização de crianças; Ensino em Ciências; } \\
\text { Ensino em Português; Ensino em Geografia e História; Ensino } \\
\text { em Matemática }\end{array}$ & 06 & $408 h$ \\
\hline C3 & Alfabetização e Letramento; Literatura Infantil & 02 & $136 h$ \\
\hline C4 & $\begin{array}{c}\text { Alfabetização de Crianças; Literatura Infantil; Fundamentos } \\
\text { Linguísticos para a Educação }\end{array}$ & 03 & $204 h$ \\
\hline C5 & $\begin{array}{l}\text { Psicomotricidade; Alfabetização e Letramento; Fundamentos } \\
\text { da Arte-Educação }\end{array}$ & 03 & $136 h$ \\
\hline C6 & $\begin{array}{l}\text { Geografia na Educação Infantil e nos Anos Iniciais do Ensino } \\
\text { Fundamental; Matemática na Educação Infantil e nos Anos Iniciais } \\
\text { do Ensino Fundamental I; História na Educação Infantil e nos Anos } \\
\text { Iniciais do Ensino Fundamental; PCC II: PPP na Educação Infantil } \\
\text { e nos Anos Iniciais do Ensino Fundamental; PCC IV: Linguagem e } \\
\text { Códigos na Educação Infantil e nos Iniciais do Ensino Fundamental; } \\
\text { PCC VII: A História na Educação Infantil e nos Iniciais do Ensino } \\
\text { Fundamental; PCC VIII: os Saberes Complementares na Educação } \\
\text { Infantil e nos Anos Iniciais do Ensino Fundamental; PCC V: A } \\
\text { Matemática na Educação Infantil e nos Anos Iniciais do Ensino } \\
\text { Fundamental; PCC VI: A Geografia na Educação Infantil e nos Anos } \\
\text { Iniciais do Ensino Fundamental; Literatura Infanto-juvenil; Arte e } \\
\text { Educação }\end{array}$ & 11 & $476 h$ \\
\hline C7 & Alfabetização de Crianças; Arte-Educação; Literatura Infantil & 03 & $204 h$ \\
\hline C8 & Corpo Movimento I: Recreação, Jogos e brincadeiras & 01 & $68 \mathrm{~h}$ \\
\hline
\end{tabular}

Fonte: Banco de dados do PERFORMA.

De acordo com o quadro acima, percebe-se uma maior expressividade na carga horária das disciplinas ofertadas nos cursos de licenciatura em Pedagogia que relacionam a Educação Infantil com outras temáticas educacionais, Partindo dessa perspectiva, constatou-se que as disciplinas que aqui se apresentam se relacionavam geralmente com as discussões do Ensino Fundamental. 


\section{autêntica}

Em outras palavras, os cursos preferem ofertar um currículo, no qual suas disciplinas se apresentam germinadas, ou seja, relacionam a educação infantil com o Ensino Fundamental e outras temáticas, destinando seus conteúdos as duas primeiras etapas da Educação Básica.

Por exemplo, tem-se o curso C6, que no Quadro 02 não havia apresentando nenhuma disciplina especifica para a Educação Infantil, e no Quadro 03 o cenário muda radicalmente, registrando onze (11) disciplinas voltadas para Educação Infantil e Ensino Fundamental. Já o curso C8 demonstra ofertar suas disciplinas relacionadas a formação docente inicial de modo próprio para cada etapa da Educação Básica.

A sondagem realizada durante esta pesquisa possibilitou a partir dessas duas categorias apontar que a organização dos currículos nos cursos presenciais relaciona os conteúdos de formação docente para a Educação Infantil, em grande medida, com a temática do Ensino Fundamental. Por sua vez o curso C8 (EaD) compreende que a Educação Infantil é uma discussão singular, devendo acontecer separadamente, registrando, portanto, a menor carga horária de disciplinas relacionadas.

\section{c) Estágio Supervisionado na Educação Infantil}

Tendo visto como os conhecimentos para a Educação Infantil estão distribuídos entre os cursos, nos quais a maior parte da carga horária é reservada a disciplinas que acabam relacionando a Educação Infantil com temas diversos do Ensino Fundamental.

Segue o próximo quadro que apresenta as disciplinas e as respectivas cargas horárias direcionadas para o estágio, momento de grande importância no percurso formativo do futuro professor da Educação Infantil, pois o estágio configura um momento de reflexão e de ação (teórico/prático)

\section{QUADRO 4 - DISTRIBUIÇÃO DAS DISCIPLINAS DE ESTÁGIO EM EDUCAÇÃO INFANTIL}

\begin{tabular}{|c|c|c|c|}
\hline CURSO & Estágio supervisionado na Educação Infantil & QTD & $\begin{array}{c}\text { CARGA } \\
\text { HORÁRIA }\end{array}$ \\
\hline C1 & Estágio I - Educação Infantil: Creche e Pré-escola & 01 & $136 \mathrm{~h}$ \\
\hline C2 & Estágio Supervisionado III - Educação Infantil & 01 & $102 \mathrm{~h}$ \\
\hline C3 & Estágio em Educação Infantil & 01 & $136 \mathrm{~h}$ \\
\hline C4 & Estágio I Educação Infantil & 01 & $136 \mathrm{~h}$ \\
\hline C5 & Estágio II - Educação Infantil & 01 & $102 \mathrm{~h}$ \\
\hline C6 & Estágio Supervisionado I em Educação Infantil & 01 & $102 \mathrm{~h}$ \\
\hline C7 & Estágio I Educação Infantil & 01 & $136 \mathrm{~h}$ \\
\hline C8 & Pesquisa e Prática Pedagógica V: Estágio Supervisionado na \\
Educação Infantil & 01 & $204 \mathrm{~h}$ \\
\hline
\end{tabular}

Fonte: Banco de dados do PERFORMA

Constata-se que todos os cursos possuem uma (1) disciplina para essa categoria, com predominância de 136h destinadas ao seu cumprimento, com destaque para o curso C8 que apresenta 204h, representando a maior carga horária destinada a promoção do estágio na investigada instituição de ensino superior. 


\section{autêntica}

Mesmo os cursos que revelaram disciplinas relacionadas ao Ensino Fundamental apresentaram estágio específico para a Educação Infantil, seguindo em conformidade com a legislação vigente, que apresenta como objetivo a formação de professores habilitados na referida etapa da Educação Básica, foco desse estudo.

Os resultados parciais desse estudo corroboram com os obtidos por Gatti e Barreto (2009), Leite e Lima (2010) e Libâneo (2011), os quais apontaram que o currículo dos cursos de Pedagogia apresenta adensamento de disciplinas teóricas e pouco trabalho com disciplinas específicas que permitam maior aproximação do futuro pedagogo com a atividade de professor que assumirá na realidade concreta das escolas, com o currículo escolar e com o cotidiano de trabalho vivenciado pelos docentes nas escolas.

Vale destacar que os estudos acima citados apresentam um mapa geral da condição da formação de professores, e mais especificamente, em cursos de Pedagogia, ressaltando suas insuficiências, ambiguidades e limites quanto ao entendimento acerca da Educação Infantil.

\section{d) Dialogando com as Categorias de Análise}

Com o intuito de apresentar um panorama geral dos cursos investigados, e assim, obter uma visão mais específica de como efetivamente é tratado o conhecimento para a Educação Infantil no interior dos currículos desses cursos de licenciatura em Pedagogia, segue-se realizando a comparação dos cursos a partir das três (3) categorias de análises já discutidas isoladamente: Conhecimentos relativos à Educação Infantil; Conhecimentos relacionados com a Educação Infantil; e, Estágio Supervisionado na Educação Infantil.

Para isso foram somadas todas as cargas horárias apresentadas no Quadro 02, Quadro 03 e Quadro 04, comparando com a carga horária total, gerando consequentemente o Quadro 05, apresentado a seguir o cenário de cada curso dessa instituição investigada no estado do Ceará.

\section{QUADRO 5 - A EDUCAÇÃO INFANTIL NOS CURRÍCULOS DOS CURSOS DE PEDAGOGIA}

\begin{tabular}{|c|c|c|c|c|c|c|}
\hline Curso & $\begin{array}{c}\text { Carga H. } \\
\text { Total }\end{array}$ & $\begin{array}{c}\text { Carga H. Ed. } \\
\text { Infantil }\end{array}$ & $\begin{array}{c}\text { \% Ch Ed. } \\
\text { Infantil/Total }\end{array}$ & $\begin{array}{c}\mathbf{N}^{\circ} \text { dis- } \\
\text { ciplinas } \\
\text { obrigatórias }\end{array}$ & $\begin{array}{c}\mathbf{N}^{\circ} \text { disci- } \\
\text { plinas Ed. } \\
\text { Infantil }\end{array}$ & $\begin{array}{c}\% \text { N } \mathbf{N}^{\circ} \text { discip. } \\
\text { Ed. Infantil/ } \\
\text { Total }\end{array}$ \\
\hline $\mathbf{C 1}$ & 3315 & 816 & $24,62 \%$ & 43 & 11 & $25,58 \%$ \\
\hline $\mathbf{C} 2$ & 3247 & 578 & $17,80 \%$ & 49 & 8 & $16,33 \%$ \\
\hline $\mathbf{C 3}$ & 3264 & 408 & $12,50 \%$ & 43 & 5 & $11,63 \%$ \\
\hline $\mathbf{C 4}$ & 3213 & 408 & $12,70 \%$ & 39 & 5 & $12,82 \%$ \\
\hline $\mathbf{C 5}$ & 3247 & 374 & $11,52 \%$ & 49 & 6 & $12,24 \%$ \\
\hline $\mathbf{C 6}$ & 3230 & 578 & $17,89 \%$ & 37 & 12 & $32,43 \%$ \\
\hline $\mathbf{C 7}$ & 3281 & 408 & $12,44 \%$ & 47 & 5 & $10,64 \%$ \\
\hline $\mathbf{C 8}$ & 3230 & 748 & $23,16 \%$ & 42 & 9 & $21,43 \%$ \\
\hline
\end{tabular}

Fonte: Banco de dados do PERFORMA.

A partir dos dados coletados e apresentados neste trabalho permitiu-se (re)conhecer a representatividade dada a Educação Infantil no estado do Ceará a partir dos cursos investigados nesse instituiçao.

Isso significa, que somada as cargas horárias destinadas a Educação Infantil de todos os cursos dessa instituição se chegou a seguinte representação 16,59\% (4.318h) do total de $26.027 \mathrm{~h}$ contabilizadas. Enquanto que em número de disciplinas, obtemos 61 (17,48\%) das 349 ofertadas no somatório de todos os cursos. 


\section{autêntica}

O presente quadro nos permite observar que mesmo entre os cursos presenciais os índices são diversos, devido a autonomia dos campi.

E embora os cursos se organizem de maneira distinta e em modalidades diversas se arrisca realizar um paralelismo entre aos oito (8) cursos investigados, lembrando que um (1) é em EaD, sob esse ponto de vista destaca-se o C1 e o C8 como cursos que apresentam maior carga horária para o tratamento de conhecimentos que se vinculam com a Educação Infantil, isso de modo geral.

Especificamente, é importante considerar que quanto menor for a carga horária destinada a disciplinas relacionadas com outras etapas e temáticas, maior é o entendimento de que a Educação Infantil possui suas especificidades, merecendo assim discussão própria. Nesse sentido, destaca-se positivamente o C8 e negativamente o $\mathrm{C} 1$.

Sendo assim, para o processo formativo do futuro professor da Educação Infantil interessa o investimento de uma carga horária especifica para tal etapa da Educação Básica. Nesse aspecto o C6 não apresentou nenhuma carga horária e o C8 registrou o maior número de horas para a promoção desse estudo.

Outro aspecto que merece ser apontado nessa discussão é que ter uma carga horária total elevada não significa que no interior do curso ela esteja adequadamente bem distribuída. Aqui registra-se o C1 (3.315) com maior e o C4 (3.213) com menor carga horária total.

Isso significa que, por exemplo, não foi o $\mathrm{C} 1$ que oferece a maior carga horária para estágio em Educação Infantil, ficando esse índice para o C8, com 204 horas e o C6 aparece com redução de horas.

Assim, diante das análises estabelecidas tem-se o C8 como o melhor curso quanto a formação do futuro professor para a Educação Infantil, se apresentando satisfatoriamente em todas as categorias de análise. Vale salientar que se trata de um curso de educação a distância.

Em segundo lugar está o C3 com apresentação mediana diante das categorias, e, o C6 se representa como o pior curso desta instituição, ambos são cursos da modalidade presencial.

Outro dado interessante é que o C8 e o C6 possuem a mesma carga horária total (3.230) e o C3 (3.264) reforçando o discurso de que não é uma questão de elevá-la para oferecer uma formação satisfatória, mas uma questão de política e de gestão dos cursos.

Desse modo, cabe aos organizadores dos centros possibilitar maior visibilidade para os conteúdos de formação de professores para a Educação Infantil, e assim, despopularizar a idéia de que para ensinar nesse nível basta ter "jeito". Tal caracterização do perfil do professor pode ser originada pela confusão nas concepções de educare cuidar que fundamentam o ensino durante essa etapa. Nesse sentido, é oportuno considerar nessa discussao o perfil definido nos documentos legais que norteiam os cursos de licencitura em Pedagogia. 


\section{DOCENTE}

autêntica

\section{CONSIDERAÇÕES FINAIS}

A pesquisa desenvolvida possibilitou o surgimento de algumas reflexões sobre o processo formativo do futuro professor para a Educação Infantil, considerando que os novos tempos impõem à profissão novas referências e exigências de qualificação profissional para o exercício do trabalho (LIBANEO, 2001).

Percebeu-se que a instituião investigada demostrou não apresentar coerência curricular, isto por que, diante da autonomia de cada campi, os cursos se apresentaram curriculamente de maneira distinta. E consequentmente, o modo de tratar o conhecimento se mostrou singular em cada curso.

Os quadros acima apresentados elencaram as disciplinas específicas para a Educação Infantil, incluindo a disciplina de Estágio, e as outras que se relacionam com essa etapa de ensino de alguma maneira.

Ao longo desse estudo se demonstrou as cargas horários destinadas as disciplinas já citadas, pois se entendeu que o quantitativo de horas reservadas a Educaão infantil seria um critério de análise capaz de dialogar com as categórias de análises, atingindo assim o objetivo geral dessa pesquisa.

E, por fim, foi promovido um diálogo entre as categorias de análise com o intuito de conhecer o tratamento dado aos conhecimentos formativos para atender o futuro professor da Educação Infantil, nesse sentido, concluiu-se que o curso em EaD apresenta os melhores resultados para a formação do professor para a Educação Infantil quando comparado com os demais cursos de modalidade presencial.

Esse resultado desconstrói a concepção existente no senso comum acerca da EaD. Isso passa a representar uma reelaboração do habitus (BOURDIEU, 2007) firmado na cultura educacional brasileira, promovendo uma práxis efetiva (VASQUEZ, 1968), a qual reestrutura a unidade teoria/prática que vem transformando os cursos de EaD nessa instituição.

\section{NOTAS}

Ficha de Caracterização das Instituições de Educação Superior (IES).

2 Para a definição das categorias de análise consideramos, inicialmente os exemplos: Gatti, Nunes (2009), Libâneo (2010) e Pimenta e Fusari (2014), as quais foram reformuladas para este estudo. 


\section{autêntica}

\section{REFERÊNCIAS}

BOGDAN, Robert; BIKLEN, Sari. Investigação qualitativa em educação: uma introdução à teoria e aos métodos. Portugal: Porto Editora, 1982.

BOURDIEU, Pierre. O poder simbólico. Rio de Janeiro: Bertrand Brasil, 2007.

BRASIL - Ministério da Educação. Congresso Nacional. Lei de Diretrizes e Bases da Educação Nacional LDBEN 9.394/96. Brasília: Centro Gráfico, 1996.

Conselho Nacional de Educação. Conselho Pleno. Resolução CNE/CP 2/2015. Define as Diretrizes Curriculares Nacionais para a formação inicial em nível superior (cursos de licenciatura, cursos de formação pedagógica para graduados e cursos de segunda licenciatura) e para a formação continuada. Brasília: MEC/ CNE, 2015.

Conselho Nacional de Educação. Câmara da Educação Básica. Resolução CNE/CEB 5/2009. Fixa as Diretrizes Curriculares Nacionais para a Educação Infantil. Brasília: MEC/CNE, 2009.

Conselho Nacional da Educação. Conselho Pleno. Resolução CNE/CP 1/2006. Institui Diretrizes Curriculares Nacionais para o Curso de Graduação em Pedagogia, licenciatura. Brasília: MEC/CNE, 2006.

CELLARD, André. A análise documental. In: POUPART, Jean et al. A pesquisa qualitativa: enfoque epistemológicos e metodológicos. Petrópolis/RJ: Editora Vozes, 2008.

CUNHA, Maria Isabel da. O bom professor e sua prática. Campinas/SP: Papirus, 1989. (coleção magistério: Formação e Trabalho pedagógico).

DAVIS, Cláudia; GROSBAUM, Marta Wolak. Sucesso de todos, compromisso da escola. In: DAVIS, C. (et an). Gestão da escola: desafios a enfrentar. Rio de Janeiro: DP\&A, 2002.p. 77-112.

FARIAS, Isabel Maria Sabino de; SALES, Josete de Oliveira C. Branco; BRAGA, Maria Margarete Sampaio de Carvalho. FRANÇA, Maria do Socorro L. Marques. Didática e docência: aprendendo a profissão. Brasília: Liber Livro, 2014.

FUSARI, José Cerchi. Formação contínua de educadores: um estudo de representações de coordenadores pedagógicos da Secretaria Municipal de Educação de São Paulo. Relatório. 1997. p. 156-200.

GATTI, Bernadete Angelina; BARRETO, Elba Siqueira de Sá. Professores do Brasil: impasses e desafios. Brasilia: Unesco, 2009.

GATTI, Bernadete Angelina. Formação de professores e carreira: problemas e movimentos de renovação. $2^{\mathrm{a}}$ ed. Campinas, SP: Autores Associados, 2000. 119p. (Coleção Formação de Professores).

GATTI, Bernadete Angelina; NUNES, Marina Muniz Rossa. (Orgs.) Formação de professores para o ensino fundamental: estudo de currículos das licenciaturas em Pedagogia, Língua Portuguesa, Matemática e Ciências Biológicas. São Paulo: FCC, DPE, 2009. 


\section{DOCENTE}

\section{autêntica}

GIL, Antonio Carlos, Métodos e técnicas de pesquisa social. 5ª ed. São Paulo, Atlas, 2002.

GONDIM, Linda Maria de Pontes. (Org.). Pesquisa em ciências sociais: o projeto da dissertação de mestrado. Fortaleza: EUFC, 1999.

LEITE, Yoshie Ussami Ferrari; LIMA, Vanda Moreira Machado. Cursos de Pedagogia no Brasil: o que dizem os dados do Inep/MEC? Ensino em Re-vista: Dossiê Formação de Professores (Publicação Semestral do Programa de Pós- Graduação em Educação da Universidade Federal de Uberlândia, MG), v. 17, n 1, p. 6993, jan/jun. 2010.

LIBÂNEO, José Carlos. Ainda as perguntas: o que é pedagogia, quem é o pedagogo, o que deve ser o curso de Pedagogia. In: PIMENTA, Selma Garrido. (Org.). Pedagogia e pedagogos: caminhos e perspectivas. $3^{\text {a }}$ ed. São Paulo: Cortez, 2011.

O ensino de Didática, das metodologias específicas e dos conteúdos específicos do ensino fundamental nos currículos dos cursos de Pedagogia. Revista Brasileira de Estudos Pedagógicos. Brasília, v. 91, n²29, p. 562-583, set/dez, 2010.

Adeus professor, adeus professora? Novas exigências educacionais e profissão docente. $5^{\mathrm{a}}$ ed. São Paulo: Cortez, 2001.

Sistema de ensino, escola, sala de aula: onde se produz a qualidade das aprendizagens? In: LOPES, Alice Casimiro; MACEDO, Elizabeth (org.). Políticas de currículo em múltiplos contextos. São Paulo: Cortez, 2006. (Série cultura, memória e currículo, v. 7).

LÜDKE, Menga; ANDRÉ, Marli E.D.A. Pesquisa em educação: abordagens qualitativas. São Paulo, EPU, 1986.

MINAYO, Maria Cecília de Souza. (Org.). Pesquisa social: teoria, método e criatividade. $32^{a}$ ed. Petrópolis/ RJ: Vozes, 2012.

MOREIRA, Antônio Flavio Barbosa. A crise da teoria curricular crítica. In PARAíSO, Marlucy A. (Org.). Antônio Flavio Barbosa Moreira: pesquisador em currículo. Belo Horizonte, Autêntica, 2010a.

A qualidade e o currículo da educação básica brasileira. In PARAíSO, Marlucy A. (Org.). Antônio Flavio Barbosa Moreira: pesquisador em currículo. Belo Horizonte, Autêntica, $2010 \mathrm{~b}$.

NÓVOA, António Manuel Seixas. Professores: imagens do futuro presente. Lisboa/Portugal: EDUCA, 2009.

PHILLIPS, Bernard S. Pesquisa social. Rio de Janeiro: Agir, 1974.

PIMENTA, Selma Garrido. (org.). Pedagogia, ciência da educação? 6ª ed. São Paulo: Cortez, 2011.

Para uma re-significação da Didática: ciências da educação, pedagogia e didática (uma visão conceitual e uma síntese provisória). In: PIMENTA, Selma Garrido (org.). Didática e formação de professores: percursos e perspectivas no Brasil e em Portugal. São Paulo: Cortez, 2008. 


\section{autêntica}

(org.). Saberes pedagógicos e atividade docente. $7^{\text {a }}$ ed. São Paulo: Cortez, 2009.

PIMENTA, Selma Garrido; FUSARI, José Cerchi. A Formação de Professores para a Educação Infantil e para os anos iniciais do Ensino Fundamental: análise do currículo dos cursos de Pedagogia de instituições públicas e privadas do Estado de São Paulo. Relatório Técnico. São Paulo, 2014.

PIMENTA, Selma Garrido; FUSARI, José Cerchi; ALMEIDA, Maria Isabel de. Cadernos de Formação: Projeto Professor de $1^{\mathrm{a}}$ a $4^{\mathrm{a}}$ série - Alfabetização. São Paulo: APEOESP, 2005.

SACRISTÁN, J. Gimeno. Poderes instáveis em educação. Porto Alegre: Artes Médicas Sul, 1999.

SAVIANI, Dermeval. Escola e democracia. Campinas/SP: Autores Associados, 2000.

TARDIF, Maurice. Saberes docentes e formação profissional. Petrópolis/RJ: Vozes, 2002.

VASQUEZ, Adolfo Sánchez. Filosofia da práxis. Rio de Janeiro: Paz e Terra, 1968.

VEIGA, Ilma Passos Alencastro. A prática pedagógica do professor de Didática. São Paulo: Papirus Editora, 1994.

ZABALZA, Miguel A. O ensino universitário: seu cenário e seus protagonistas. Trad.: Ernani Rosa. Porto Alegre: Artmed, 2004. 